long ago; but, so far as I know, we have obtained no information by such means, except negatively, on which to found a theory, or to obtain a guide to practice. The total amount of knowledge consists in this: that at varying intervals after the occurrence of more or less violent local injury, and occasionally -but in our latitude very rarely -independently of injury, we observe rigidity of the muscular system, commencing with the muscles of the jaw and extending to the neck, trunk, and finally to the extremities; that it is accompanied by great pain in the contracted muscles, a quick pulse and respiration, and constipated bowels; and that it terminates, in from two to six or eight days, in death. Such is nearly the sum total of our knowledge of tetanus, and it may be doubted whether we are even now occupied in the right path of inquiry. We fix our attention on the local spasm of the muscular frame, as though that condition of the system constituted the essence of the disease, of which it is only a symptom. We rather search for remedies that will abate spasm, than for such as will attack its cause. The above case exemplifies negatively this fact. The boy died of tetanus, but not of spasm. At no period of his case was the contraction of his unuscles so rigid as to cause pain of a severe character. He complained of his arm; he suffered from a sense of illness; he desired to be let alone, and not to be disturbed; his expression betokened serious illness; but he did not die from pain nor from spasm: he gradually sank from utter prostration of nervous power, which every remedy employed was incompetent to contend against. And it is by no means uncommon to observe, towards the close of life, that the most prominent symptom of the disease-namely, muscular rigidity-gradually subsides, while the real disease advances towards its fatal crisis. In the whole range of dis. ease, I do not recollect any evidence of the existence of what we term the nervous system more remarkable or more conclu. sive than is derived from the influence of anæsthetics in tetanus. How absolutely is the morbid influence of the nervous system on the heart and respiratory system suspended by chloroform! and how suddenly too! The pulse falls to its natural standard, the equilibrium of respiration is restored, all expression of suffering subsides under the reality of tranquil sleep. So com. plete is the external manifestation of health, that it would astonish a bystander, ignorant of the nature of the case, to be assured that in a few days, possibly a few hours, it would terminate in death. Suspend the remedy, remove the influence of the anæsthetic agent, and the entire train of fatal symptons starts, as it were, into existence-the pulse rises, the respiration is quickened in proportion, and the muscular spasm, with its usually inseparable companion, pain, become again dominant. Nor do we observe that the disease, to whatever extent it may have reached, is retarded or even diminished by the treatment. On the centrary, its progress is unremitting; and both the violence of the spasm and the severity of the pain are regenerated with an increase of intensity proportioned to the duration of time during which they have been suspended by anesthetic agency. In the above case, I was fully prepared to test the curative properties of the woorara poison, as recorded by Mr. Wells and recent French writers; but I really had no excuse for its employment. The boy did not die either from or with spasm; aud I cannot persuade myself that we shall ever discover in the woorara poison a curative property capable of rousing the vital powers, already oppressed hy mysterious morbid actions going on within the frame. Still, I am quite prepareal to acknowledge that all reasoning, more especially on a subject so obscure is tetanus, sinks in comparison with practical observation. Other authorities may view the subject in a different light; and it will prove no small accession to our knowledge should we discover in this or in any other untried acent the power to arrest so hitherto fatal a disease as that which forms the sulject of the above brief remarks.

Oprum and Begradonna Prasters. - Mr. A. F Haselden, having olserved the ineonveniences attending the use of these plasters of the Pharmacopoia, of which inost medical practitioners are very sensible, (viz, that the preparation runs beyond the margin of the leather, or frequently penetrates it, and stains umpleasantly the clothiug, proposes, in a recent numle: of the Pharmaceutical Journal, methods of obviating them. He recommends the use of resin plaster instead of gum thus, and unorphia in place of opium. For the opium plaster he proposes the following formula. which has been successfully employed:--Lead plaster, six ounces; resin plaster, four onnces; acetate of morphia, one drachm; acetic acid and water, of each four àrachms. For belladonna plaster, the following:-Lead plaster, six ounces; resin plaster, four ounces; atropine, two grains; acetic acid, two drachms; water, six drachms.

\section{A WINTER AT MENTONE, NEAR NICE.}

By J. HENRY BENNET, M.D.,

PHYSICIAN-ACCOUCHECR TO THE ROYAL FREE HOSPITAL, ETC.

A sIx months' residence on healthy ground at Mentone, one of the most sheltered winter stations in the south of Europe, has given me practical information concerning its climate and health capabilities whish will, I presume, be acceptable to many, and which I will endeavour briefly to embody.

Mentone is a small Italian-like town of 3000 inhabitants, situated in latitude $42^{\circ}$, twelve miles east of Nice, at the foot of the Maritime Alps. It is the first station out of Nice on the Cornice road to Genoa, and is the largest town of the principality of Monaco, which has recently been annexed to France along with Nice.

The Gulf of Genoa is formed in its western half, between Nice and Genoa, by the Maritime Alps, the immense masses of which descend to the sea so abruptly in some places as to leave no shore, their beetling crags terminating directly in the sea. This is the case immediately behind and to the eastward of Nice. Owing to this circumstance, there was formeriy nor continuous land-road from Nice to Genoa. The one that now exists is of recent origin, and has been carried in many places over and along high mountains and precipitous cliffs. Where the shore exists, it is generally a mere rocky, sandy ledge, from which the mountains rise directly.

On leaving Nice for Genoa, the road at once begins to ascend the Turbith, a mountain about 3000 feet high, and one of the spurs that run directly into the sea. It is at the foot of this mountain that Nice lies. The ascent occupies two hours, the descent about the same time, and at its ternination is situated the town of Mentone. When the traveller has crossed the Turbith and begins to descend, a glorious panorama opens before him. The higher mountains, receding from a beautiful bay, open to the south-east, and form a magnificent amphitheatre, which at its centre recedes five or six miles from the sea. The bay, about four or five miles in circuit, is divided into two unequal portions by a hill, which gradually slopes to the sea, and on the sides of which climb the houses that constitute the old town of Mentone. The space between the sea and the receding mountains, which are between 3000 and 4000 feet high, is occupied by a series of lower hills, which slope gently to the shore, and which are divided by numerous ravines and torrential valleys. The higher range of mountains, of a greyish-white, is generally precipitous and bare, being destitute of vegetation. The lower hills are densely covered with trees and present at a distance the aspect of forest-clad, rounded ridges, geutly descending to the sea.

Thus the bay in the centre of which Mentone is placed, with its background of rising olive-clad hills, is thoroughly protected from the north-west, north, and north-east winds by the higher mountain range. Beyond the latter are the still higher moun tains of the Col di Tende, which constitute the main mass of the Maritime Alps, extending for sixty miles inland, and which, no donbt, increase the protection. Indeed, the bay is only open to the south and south-east; consequently, the mistral, as a west or north-west wind, is not at all felt; but as a south-west wind it is partially felt. The north wind passes over the higher mountains and falls into the sea at some dis. tance-a couple of miles-from the shore. When it reigns, there is a calm at Mentone, and the sea near the beach is also calm, whilst at some distance from the shore it may be crested and furious. This I have of ten witnessed from the hills. The north east wind leaves the town and hills untouched, but, when strong, raises a heavy sea; whilst the east and southeast (the levant), and the direct south (the sirocco), blow directly into the bay, and always occasion a heavy, rolling swell.

Owing to the complete protection from the west, north-west, north, and north-east winds, and owing to the reflection of the sun's rays from the sides of the naked mountains which form the amphitheatre, the climate of Mentone is rather warmer than that of Nice-indeed, warmer than that of any part of the northern or central regions of Italy. This fact is proved by the presence of groves of large, healthy lemon trees, which occupy the sheltered ravines and the warmer hill-sides, wherever water can be obtained; constant irrigation, summer and winter, being necessary for their cultivation. They are, in 
deed, much more numerous than the orange trees, although many fine plantations of the latter are found throughout the district. Orange trees can bear without injury several degrees of frost, whereas one degree destroys the fruit of the lemon tree, and two or three destroy the tree itself. Olive trees, which can bear with impunity seven or eight degrees of frost, occupy, generally, the summits and sides of the lower hills, presenting at a distance the appearance of sombre evergreen forests; at a higher level still, on the highest regions of the lower hills, and climbing up the base of the higher or back range, are forests of stunted pines.

The orange tree flowers but once in the year, and bears one crop of fruit only. The lemon tree, on the contrary, flowers all the year through, and bears at Mentone four distinct fruit crops. Its existence in groves of large trees, from twenty to thirty or more years old, without artificial protection, and its profitable cultivation throughout the year, prove that there must have been freedom from severe frost for many years. I was told, however, that about twenty-five years ago nearly all the lemon trees in the country were destroyed in one night, which may account for no very old trees being seen.

During the last winter the thermometer descended to zero several nights consecutively near the sea-shore, slight films of ice forming on flagons of water on the road and near the torrents, and the highest mountain range being covered with snow. This alarming state of things occasioned profound dismay in the minds of the natives, whose principal riches are the lemon groves. For several nights many of them sat up, in the greatest consternation, watching the thermometer. Indeed, there was a complete panic with reference to this lamentable and unheard of condition of the weather. Such feelings and fears plainly indicated that frost and snow were very unusual and unwelcome visitors. We often had snow for a few days on the summits of the higher mountains, but on this occasion a few flakes appeared on the shore level. On no other part of the Cornice road do lemons grow thus freely. At Cannes they are all but unheard of, and at Nice they only grow in sheltered and protected sites, and not luxuriantly.

Another evidence of the exceptional warmth of the climate is the presence of large caronba trees, and of large euphorbias. The latter grow in many places to a great size, like large rhododendron bushes. At Nice I only found them as luxuriant in one spot, the south-east side of the castle. Owing to the absence of frost, many of our garden flowers, which are cut down by the first frosty night, continue to flourish and bloom all the winter through. This is the case, for instance, with the geranium, the heliotrope, and the verbena, which continue to flower freely throughout the winter in the open air in many gardens.

The geological features of the country are very interesting, and much may be observed in a small compass. The high range of mountains which form the amphitheatre are of secondary Oolitic or Jurassic unstratified limestone. At both the eastern and western extremities of the Mentone bay this formation juts out into the sea. At the eastern extremity, the road to Genoa is cut out of the side of the mountain, and ascends to a great elevation, crossing a deep ravine by a bold bridge, the Pont St. Louis. A short distance on each side of this point are observed the strata which replace the chalk formation in Italy. Then commences the tertiary system by a well-developed nummulitic limestone, full of nummulites, which is followed by other representatives of the miocene, pliocene, and pleistocene groups. These strata are observed on both sides of the Pont St. Louis, in the same order, eastwards towards Venlimiglin, and westward to Rouabruna, at the base of the Turbith ascent. At both these points appear the pleistocene boulder drift. Thus the lower hills which occupy tho ground, as it were, of the Mentone amphitheatre, represent from east to west the different strata between the secondary Jurassic oolite and the post-tertiary boulder drift.

The water which falls on the higher mountains, in finding its way to the sea, has worked deep ravines, which expose the structure of the tertiary rocks, and have formed numerous narrow valleys, by which access is obtained to the higher mountains, and to three or four small picturesque towns or villages therein built. These ravines form, as we shall see, an important feature in the sanitary history of Mentone. Owing to the backbone of the district, as it were, being limestone, the water is everywhere very hard, and the springs considered the purest are loaded with lime. Treated with oxalic acid, the water gives a most abundant precipitate, ever when taken from springs in the sandstone rocks. I had to meet this diffculty by giving distilled water or rain water to several patients. In other cases the hardness of the water was evidently beneficial, as, for instance, in cases of chronic diarrhoa.
As is usually the case in the south, the rain geverally falls in great quantities in a limited space of time, filling the beds of the torrents with enormous volumes of water, which carry great masses of stone with them from the mountains. There the watercourses are, at other times, as in Central and Southern Italy, mere rivers of stones, with a thin stream of water trickling through the middle. On one night in December, $4 \frac{1}{2}$ in. fell in ten hours. The total rain-fall last winter was 23.68 in., from October 9 th to April 21st: October, 8.02 in.; November, $2 \cdot 21$ in.; December, 6.96 in.; January, $3 \cdot 24$ in.; February, -18 in.; March, 1.26 in.; April, 1.81 in. These data were given me by a friend, Mr. Smith, of Rome, who kept an accurate register. According to my own observations, it rained in November five days, in December five, in January four, in February one, in March six, and in April, up to the 23rd eight days; in all, twenty-nine days, from Nov. 3rd until April 23rd. In October I was told it rained nearly every day. I constantly saw it raining on the upper hills, or a few miles out at sea, when it was quite clear and fine at Mentone-a fact easily explained, and which partly accounts for the peculiar dryness of this place.

During the six months that I was at Mentone I never once saw a fog, day or night, morning or evening. Generally speak. ing, the sky was clear, and the sun shining in the heavens like a globe of fire. So powerful were its rays, that even in December or January it was disagreeable to walk in it without a lined parasol or umbrella. Owing to the power of the sun, the freedom from fog, the slight amount of rain, and the dry, rocky character of the soil, the air was usually very dry; so much so, that a wet towel would dry in the open air, out of the sun, within an hour or less, at any time in the winter, except when it rained or the sky was obscured.

And yet it was winter at Mentone. The nights were cold, the thermometer generally falling to between $40^{\circ}$ and $45^{\circ}$, and sometimes, in bad weather, below $40^{\circ}$, during four monthsDecember, January, February, and March. During the day it was generally cold in the shade and when the sun was obseured by clouds, and it always became cold as soon as the sun went down. The heat was evidently sun heat. In a south room whenever the sun was on the room, the window conld be left wide open, and, without a fire, the thermometer generally remained at $60^{\circ}$ or thereabouts. As soon as the sun disappeared, however, the window had to be shut and a good fire lighted. In midday, also, the north rooms on the same floor, during these months, were generally six, eight, or ten degrees colder than the south. Again, immediately after the sun disappeared behind the mountains there was generally a difference of eight or ten degrees in the temperature of the atmosphere and whenever the sun was permanently obscured by clouds, it became chilly and cold, and the complaints against the climate were loud and numerous. Fortunately the bad weather never lasted more than three, four, or five days. At the end of that time the sky was again clear, the sun again careered through the heavens like a blazing fire; in a couple of hours the ground was dry, and out-door life again began.

The vegetation showed the influence of a powerful sun warming a chilly atmosphere. The deciduous trees lost their leaves in December, as soon as the nights became cold, and did not regain them until April, when they were becoming warmer. The green forest-clad appearance of the hills and valleys in midwinter was owing entirely to the evergreen, olive, orange, and lemon trees. The few deciduous trees were mere dry sticks until April. On the other hand, in sheltered situations exposed to the south, the heat of the sun during the day so warmed the soil that it had not time to cool at night, and such situations become regular forcing-beds, producing violets in December, anemones in January, and all our spring flowers early in February. Where the sun did not penetrate, on the other hand, the ground-vegetation remained torpid, like the deciduous trees, till March. As, however, the sun-exposed localities were very numerous on the sheltered lower hills and in protected valleys away from the sea, the ground-vegetation early became very luxuriant and abundant, offering great resources to the botanist and florist. Indeed, in the warmer valleys the only winter was the rainy days.

From what precedes, it will be perceived that the characteristics of the climate of Mentone, as evidenced during last winter-an unusually severe one,-were the following: the absence of frost; the absence of fogs; the paucity of rainy days; the clearness of the sky; the heat and brilliancy of the sun when it did not rain; a rather cool or chilly night-temperature; a bracing coolness of the atmosphere throughout the winter out of the sun's rays; and when, on the contrary, the sun was obscured by clouds, and rain fell, as miserable and chilly a state of things as a drizzling November day in Eng. 
land. As, however, during nearly six months, rain only fell on twenty-nine days (about one in six), and then often not during all the day, and as the other days were uniformly bright, clear, and sunshiny, five days out of six, throughout the winter, exercise in the open air could be prudently taken, with great satisfaction and benefit, and that from breakfast to dinner. Notwithstanding the complete protection from the north and west, the wind was often very high; it generally seemed to come from the south-east, the open quarter, probably owing in part to the land-losked character of the district; but even when it was present, the mountain valleys and the more internal hills were quite sheltered and protected. There certainly was, however, anything but the atmospheric stagnation which has been mentioned as peculiar to Mentone The second or eastern bay was decidedly better protected from wind, and appeared to be warmer also, than the western, owing to the monntain rising immediately behind the honses which line the shore.

Such a climate is a favourable specimen of what botanists call the warmer temperate zone. Plants live which frost kills; many annuals in a colder region become perennials; and many forms of vegetation new to the more northern flora make their appearance. It is the Mediterranean climate, but that of the more favoured Mediterranean regions. In Italy, for instance, the most protected southern parts must be reached to find the same immunity from frost. Mentone, also, is a little warmer, and more protected from wind, than its neighbour, Nice, and much more so than Cannes, although the general features of the climates must be the same, for they are only a few miles apart. It is the question of fruit walls in the same orchard, one a little more sheltered and protected than the others, but all being turned towards the south. At Nice, however, there are situations, such as the Cinney and the Carabacel, for instance, in which the protection is greater than in the town itself, and which thus assimilate to Mentone.

The foreign population at Mentone numbered about three hundred, and contained representatives of nearly all the European nations. The French and English were, however, the most numerous, each family generally containing one invalid. Most of the latter were suffering from pulmonary consumption. The results of their winter's residence were such as might be expected from the above details. Those who were in the early or even secondary stages of the disease, and had vitality and constitutional stamina left, mostly did well. I saw in several young females well-marked, crude tubercular deposits disappear, gradually absorbed. In several cases of accidental phthisis in middle-aged, over-worked men, the amelioration was still more apparent. Well-marked cavities became partly or entirely cicatrized, and the constitutional symptoms gradually subsided, the general health and strength steadily improving. Those who were in the latter stages of the disease, on the contrary, appeared to derive but little benefit from the change. The disease seemed to proorress slowly, but steadily. They suffered from the cold and the wind, and especially from the occasional outbreaks of wet, chilly weather. Moreover, they felt bitterly the absence of home comforts, and their separation from friends. Several dropped off in the course of the winter, as they would have done at home, from hæmorrhage, from pleurisy, from bron. chitis, or diarrhœa. In their case, it appeared to me that little was gained by the change of climate. They could not avail themselves of its bracing capabilities for out-door life and enjoyment, and felt the rariations, against which they could not protect themselves as well as at home. Such patients, I should say, are better at home, or in a warmer climate than that of Mentone, or Italy generally-Madeira, for instance, where the temperature is said never to fall below $56^{\circ}$.

Several patients who always suffered from bronchitis in Eng. land, were quite free from it at Mentone, owing probably to the dryness of the atmosphere. This remark applies to other similar climates. I met an old friend at Nice, a London phy. sician, aged fifty-four, who abandoned London four years ago, owing to repeated attacks of winter bronchitis, which at last led to very serious complications. He made a winter settlement at Nice, and has there passed the cold season ever since, perfectly free from all bronchial mischief, and in flourishing health. In several cases of this description, the attempt to spend the winter in England was attended with a return of the bronchial affection with its usual severity. In one phthisical case that I saw, a gentleman aged forty-four, with softened tubercles, who had suffered from sore-throat and bronchitis for nearly four years in England, lost all cough and laryngeal irritation after three months' residence at Nentone, and had no return during the winter or spring.

It is easy to understand that a dry, bracing, cool, invigo. rating climate such as $\mathrm{I}$ have described should have a beneficial influence on the respiratory mucous membrane of the persons who have still some of the vital power of youth or some consti. tutional stamina left. When we add to this, all but daily exercise in the open air thronghout the winter, in the midst of magnificent scenery, removal from the cares, anxieties, and duties of ordinary life, pleasant social intercourse with fellow. sufferers and their families, all tuned to the same unison of cheerful and hopeful resignation, we certainly have united all the hygienic influences calculated to renovate the general health, and to arrest the development of tubercular disease. Indeed, to me it is a question whether a warmer and milder winter climate, which is only to be found in a tropical or sub-tropical region, is not less favourable to the recovery of bealth under such circumstances, always provided rigid attention be paid to the precautions necessary in a climate where the temperature so constantly varies. Heat and moisture debilitate and relax the economy; moderate cold and a dry atmosphere invigorate and strengthen it: and, in the treatment of phthisis, the renovation of the general constitutioual health is of primary importance.

To derive that benefit, however, from the climate of Mentone, and of the south of Europe generally, which it is capable of affording in pulmonary consumption, the most rigid adherence should be paid to the hygienic rules peculiar to these regions during the winter season. It should never be forgotten that in winter the heat is sun-heat, and that the air, barring its in. fluence, is usually cold. Warm clothes and woollen outer garments should be used. In dressing for out of doors, a thermometer, placed outside a north room, should always be consulted. The hours for ont-of-door exercise should be between ten and four, and the return should be so arranged as to serure the arrival at home before sunset. The Italian physicians appear to attach a mysterious noxious influence to the hour of sumset. In such a climate as that of Mentone, Nice, \&c., I am persuaded the danger is merely in the sudden lowering of the temperature after sunset, which exposes to sudden chills, from the pores of the skin being often open at the time through previous exercise. As the same danger exists even in midday in passing accidentally from the sun to the shade, it is always necessary to be dressed for the latter. The invalid should inhabit a south room, and never go into a north room unless previously warmed by a fire. The one is summer, the other winter. When the weather is bad, he should make a large fire, and rigorously stay at home until it changes. Sunshine and warmth are sure soon to reappear, and thus to bring the confinement to a close. After two or three days of chilly rain, sore-throats and colds begin as in England, but then the sun again shines, and they usually die away. All dinner and evening parties should be strictly forbidden. The invalid must be in by sunset, and not leave home again until the following morning. The improvement will be generally the more decided the more these rules are observed. Lastly, exercise and out-door life must not be carried so far as to produce permanent lassitude. Several of the patients around me, and I myself, fell into this error-mone easily committed, owing to the great attractions to out-door life, and the injunction generally made to take daily exercise if possible.

With these precautions, the climate is safe and beneficial; without them, it is unsafe and treacherous. This is evidenced by the great mortality of the natives of the Nice and Mentone districts, and of Italy generally, by pneumonia and plenrisy, two of the commonest maladies. Being badly clothed, never making fires, and ignorantly braving these atmospheric changes, the lower orders are constantly exposed to chills, and succumb in great numbers to these maladies, treated, as they are, by bleeding every few hours. Persons in the latter stages of phthisis more especially suffer from the slightest dereliction of the above rules, which they are not always the most careful to follow.

The exceptionally mild climate of Mentone, even for the latitude in which it is placed, is the result of a double cause. It is occasioned, on the one hand, by the complete protection afforded by the Maritime Alps from the north and northeasterly winds; on the other, by a direct southern exposure, and by the prevalence in these seas of south-westerly winds. The entire western coast of Italy participates, but in a less degree, in these advantages. The protection from the northeast throughout this coast is afforded by the Apennines, which divide the peninsula from north to south, like a midrib. As a result of this disposition the western coast of Italy is much warmer in winter and cooler in summer than the eastern. The latter, not being protected by the Apennine chain, is exposed to the full influence of the north-easterly winds, which blow from Continental Europe, and which are both very cold in winter and very warm in summer. 
The resources of Mentone for visitors are entirely in the ontdoor life. The scenery, as I have stated, is most grand and imposing in the mountain back ground, and most picturesque and romantic in the nearer hills and coast outline. Every ravine, every villey is a path of grent loveliness, ascending gently towards the higher range. The flora is very abundant, and most of our garlen spring flowers grow wild in great luxuriance. The geological aspects of the country are very instructive, and afford occupation and amusement to those in. terested in such pursuits. The great invalids mostly kept to the sea-shore; those who were stronger mounted sure-footed donkeys, and ascended the mountain paths as far as their strength permitted; whilst the robust and valid members of the community tried their pedestrian powers by ascending the higher mountains in various directions. Whenever the sun shone there were protected valleys and sunny mountain nooks, where at all times, in December or January, as well as earlier, we were sure to find warmth, a quiet atmosphere, and flowers. What with these occupations, books and newspapers interchanged, and the harmonious intercourse of countrymen united by the bond of cormon origin and suffering, the winter passed pleasantly along, merely saddened occasionally by the loss of one of the more hopeless sufferers.

There is an English clergyman, the Rer. Mr. Morgan, settled with his family at Mentone, where he has built a house, whose kind and intelligent sympathy is always enlisted in behalf of his countrymen, and whose presence is a boon to all. Each season since the English began, three or four years ago, to visit Mentone, has brought one or more English physicians, either as the companions of sufferers, or as invalids themselves, and the principal Italian physician, Dr. Bottini, is a skilful and ex. perienced practitioner.

There are now many pretty and commodious villas and apartments to let furnished. There are also three hotels and two boarding-house hotels. Chlericy's Hotel de la Pension Anglaise, where I myself spent the winter, is the largest and best modern house in Mentone, and admirably situated. In these latter establishments, the terms are about seven francs a day; in the hotels, rather more. The road to Mentone is by Paris, Marseilles or Toulon, and Nice; the expense from $£ 10$ to $£ 15$.

In conclusion, I may ald, that I myself was so well pleased with Mentone that I should return there, were it not for the love of change, which will probably impel me, next winter, to Algiers or Spain, in search of a still better climate. Should I discover such a one, I shall not fail to communicate the discovery to my readers. This desire for change is quite a feature in the invalid population one meets with in the south of Europe. It is probahly beneficial in its operation, by giving the mind fresh objects of interest to take the thonghts from self, and from the many sacrifices which the health exiles from home and their companions have to make. The difference between the smiling sunshine of a Mentone winter (a mere long English October) and our eight months' dismal winter season is very great, and yet there were few of the cheerful Mentone exiles who would not gladly have returned to our cloud-obscured island, had it been prudent and possible.

The Ferns, Weybridge, Surrey, June, 1860.

ON A CASE OF

\section{EXCISION OF DISEASED AND ANCHYLOSED KNEE, WITH GOOD RESULT.}

BY CHRISTOPHER HEATH, F.R.C.S.,

$$
\begin{gathered}
\text { DEMONSTRATOR OF ANATOMY AT THE WESTMINSTER HOSPITAL } \\
\text { SURGEON TO THE ST. GEORGE'S AND ST. JAMES'S } \\
\text { DISPENSART, ETC. }
\end{gathered}
$$

Since the operation of resection of the knee-joint may be said to be still upon its trial, I think it right to publish the following case, which presents some peculiarities. In order, however, to prevent mistakes as to the statistics of the operation, I should say that this case is included amongst those tabulated by Mr. P. C. Price in his paper read before the Medical Society of London.

Charles $\mathrm{P}-$, aged eleven years and a half, was brought to me at the St. George's and St. James's Dispensary, on the Sth of June, 1858, with the following history. He had scarlet fever six years ago, and the left knee then became swollen, and continued so for three years; the boy being able, however, to walk about. Three years ago an abscess formed on the out. side of the joint, which was opened by Mr. Blagden, who applied a straight splint, and the boy was kept in bed three months, after which he was able to walk about again, the wound still discharging slightly. About twelve months ago, an abscess began to form on the inner side of the knee, and he was taken to one of the metropolitan hospitals, where he was admitted as in-patient on the 15th of September, 1857. The abscess burst, and another formed. The actual cautery was applied over the joint, and he was discharged at the end of April, 1858, as the parents would not consent to his undergoing amputation of the thigh.

Both mother and child agree in saying that on admission in to the hospital the knee was straight and rather stiff, but upon his coming ont it had become bent to just a right angle, which is its present condition. There is an open sore on each side of the joint, and one over the middle of it, which discharge freely. The knee is firmly fixed at a right angle, and is slightly swollen. The boy suffers pain at night, but is otherwise in pretty good health, having improved since he has been at home. The accompanying sketch from a cast made at the time will give an idea of the condition of the parts :-

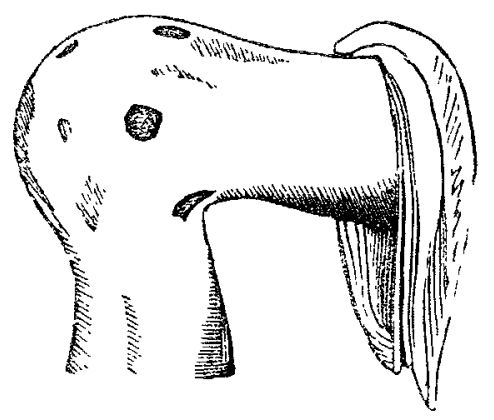

There being evidently firm anchylosis of the joint, upon careful examination under chloroform, and the probe leading to bare bone through each of the sinuses, resection of the joint was evidently the only course to be pursued; and this having been explained to the parents, they consented to its performance.

Operation June 29th, 1858.-Having made an $\mathbf{H}$-incision, I attempted to turn up the patella with the flap, but found that bone firmly fixed to the outer condyle, and the femur also anchylosed to the tibia. I therefore removed the whole joint in a wedge, carrying the saw immediately behind the patella and throngh the upper part of the tibia. As the parts did not come quite readily in apposition, I next removed a slice about half an inch thick from the femur, when the cut ends came easily together. The edges of the wound were brought together with a few stitches, and the limb was placel on a straight iron splint with a few straps and a bandage. Two small abscesses were opened during the operation, and a quantity of gelatiniform synovial membrane was removed. Some oozing took place in the evening, but was easily arrested.

The boy, although feeble, made a good recovery, the splint being removed for the first time on the 10th of August, when a gutta-percha one was substituted. In September, a small abscess formed over the head of the tibia, and the limb was replaced for a few days on the iron splint, an inside splint being also adapted to it, to counteract a tendency to bow outwards.

On the 4th of October the boy was sent to the Margate Infirmary, with the limb straight and in a gutta-percha splint. The sinuses below the knee continued to discharge slightly; the rest of the wound was entirely healed.

The portion of bone removed showed erosion of the articular cartilages and thickened synovial membrane. On maceration for a short time, it appeared that the anchylosis between the patella and the condyle, and also on the inner side between the femur and tibia, was only fibrous, but on the outer side bone had been developed, as was seen on a section. The second slice of femur was found to have included the whole of the epiphysis.

The boy returned from Margate in December, 1858, very much improved in condition. The limb was in grood position, though a little bowed outwards. Two sinuses over the head of the tibia continued to discharge rather offensive matter.

May, 1859. - Boy much improved in health, and able to get about with the help of a stick only. The two sinuses over the tibia continuing to discharge, notwithstanding the use of in. jections, \&c., I gave him chloroform and laid them open. Found that they both led into a cavity in the tibia, which was 